\title{
KARAKTERISTIK PELUAHAN SEBAGIAN (PARTIAL DISCHARGE) PADA ISOLASI KARET SILIKON (SILICONE RUBBER) MENGGUNAKAN SENSOR EMISI AKUSTIK
}

\author{
Anwar Solihin $^{1}$, Jannus Maurits Nainggolan ${ }^{2}$, Dikpride Despa ${ }^{3}$ \\ Jurusan Teknik Elektro Universitas Lampung, Bandar Lampung \\ Jl. Prof. Sumantri Brojonegoro No.1 Bandar Lampung 35145 \\ 12anwarsolihin@yahoo.com \\ ${ }^{2}$ mauritus24@gmail.com \\ ${ }^{3}$ despa@eng.unila.ac.id
}

\begin{abstract}
Abstrak- Kabel merupakan peralatan listrik yang rentang kerusakan pada saat pemakaian instalasi. Terjadinya hubung singkat pada instalasi listrik industri biasanya disebabkan karena sambungan kabel yang tidak baik ataupun karena rusaknya isolasi kabel. Oleh karena itu, perlu dilakukan pengujian terhadap komponen listrik. Salah satu cara mendeteksi kerusakan dini pada isolasi kabel adalah dengan pengujian peluahan sebagian. Analisa peluahan sebagian jenis rongga (Void) pada penelitian ini menggunakan metode emisi akustik. Dari hasil analisis diketahui bahwa frekuensi dominan dari karet silikon pada jarak $24 \mathrm{~mm}$ adalah juga disekitar $60 \mathrm{kHz}$ dan pada jarak $36 \mathrm{~mm}$ adalah disekitar $60 \mathrm{kHz}$, dimana nilai arus bocornya adalah pada jarak $24 \mathrm{~mm}$ sebesar 28-31 mA sedangkan pada jarak $36 \mathrm{~mm}$ nilai arus bocornya sebesar 32-33 $\mathrm{mA}$.
\end{abstract}

\section{Kata kunci_Peluahan rongga, Emisi Akustik, Karet Silikon.}

Abstract - Cables are electrical equipment that ranges damage during installation usage. The occurrence of short circuit in the electrical installation industry is usually caused by bad cable connection or because of damage to cable insulation. Therefore, it is necessary to test the electrical components. One way to detect early damage to the cable insulation is the partial discharge testing. Analysis of partial discharge void type in this study using acoustic emission method. From the results of analysis show that the dominant frequency of silicone rubber at a distance of $24 \mathrm{~mm}$ is around $60 \mathrm{kHz}$ and at a distance of $36 \mathrm{~mm}$ is around $60 \mathrm{kHz}$, whereas the magnitude of the leakage currents are $28-31 \mathrm{~mA}$ at a distance of 24 $\mathrm{mm}$ and around 32-33 $\mathrm{mA}$ at a distance of $36 \mathrm{~mm}$.

\section{Keywords-Discharge void, Acoustic Emission, Silicone Rubber.}

\section{PENDAHULUAN}

\section{A. Latar Belakang}

Kebutuhan energi listrik terus meningkat seiring dengan perkembangan pola hidup masyarakat, Perusahaan Listrik Negara (PLN) dituntut untuk memberikan suplai energi listrik yang diperlukan untuk memenuhi kebutuhan masyarakat. Oleh karena itu, untuk menjaga sistem tenaga listrik agar tetap memberikan suplai energi listrik yang dibutuhkan, peralatan listrik yang digunakan harus mampu menunjang kinerja dari sistem tenaga listrik. Adapun salah satu peralatan listrik yang harus diperhatikan dalam penyaluran energi listrik yaitu kabel tegangan tinggi/menengah.

Kabel merupakan bagian dalam instalasi listrik yang berguna untuk menyalurkan energi ke peralatan yang menggunakan energi listrik, kabel juga merupakan peralatan rentan kerusakan dalam keamanan instalasi. Terjadinya hubung singkat pada instalasi listrik industri biasanya disebabkan karena sambungan kabel yang tidak baik ataupun karena rusaknya isolasi kabel.

Salah satu cara mendeteksi kerusakan dini pada bahan isolasi kabel adalah dengan pengujian peluahan sebagian. Peluahan sebagian pada isolasi kabel diduga dapat menjadi pemicu terjadinya kerusakan. Hal ini terjadi karena peluahan sebagian akan mengakibatkan isolasi pada kabel akan mengalami pemburukan pada lokasi terjadinya peluahan sebagian. Pemburukan yang terjadi, jika dibiarkan berlangsung terus menerus dapat menjadi pemicu terjadinya tegangan tembus (breakdown) pada lokasi terjadinya peluahan.

Teknik pengujian emisi akustik merupakan salah satu pengujian yang tidak merusak (Non Destructive Testing). Beberapa pengujian tidak 
merusak lainnya adalah Ultrasonic, X-Ray, Edy Current, Liquid, dan Thermographic. Metode emisi akustik (acoustic emission) merupakan salah satu aplikasi pengujian tidak merusak yang paling banyak digunakan saat ini.

Oleh karena itu, penelitian ini dilakukan untuk mencari sifat kegagalan dan karakteristik gelombang peluahan dari bahan isolasi karet silikon yang digunakan di peralatan listrik. Analisis peluahan sebagian berguna untuk mendiagnosis tingkat degradasi isolasi polimer. Fenomena pra-kegagalan dapat dideteksi dengan pengamatan dan pengukuran pulsa peluahan sebagian. Mempelajari peluahan sebagian menjadi penting karena dengan mengetahui tingkat peluahan sebagian maka suatu isolasi dapat diperkirakan kondisinya.

B. Tujuan

Tujuan dari penelitian ini adalah:

1. Mendapatkan karakteristik gelombang peluahan sebagian pada isolasi karet silikon yang mencakup bentuk/besar tegangan peluahan dan arus bocor.

2. Mendapatkan besaran frekuensi $(\mathrm{Hz})$ dominan peluahan sebagian yang terjadi di dalam rongga udara pada karet silikon.

\section{TINJAUAN PUSTAKA}

\section{A. Kegagalan Isolasi}

Isolasi berfungsi untuk memisahkan bagianbagian yang mempunyai beda tegangan agar diantara bagian-bagian tersebut tidak terjadi lompatan listrik (flash-over) atau percikan listrik (spark-over). ${ }^{[1]}$ Kegagalan isolasi pada peralatan tegangan tinggi yang terjadi pada saat peralatan sedang beroperasi bisa menyebabkan kerusakan alat sehingga kontinuitas sistem menjadi terganggu. Dari beberapa kasus yang terjadi menunjukkan bahwa kegagalan isolasi ini berkaitan dengan adanya peluahan sebagian (partial discharge).

\section{B. Peluahan Sebagian}

Peluahan sebagian merupakan peristiwa peluahan listrik lokal yang menghubungkan sebagian isolasi di antara dua konduktor. Peluahan tersebut dapat terjadi baik di permukaan maupun di tengah bahan isolasi. Peristiwa ini ditandai dengan pelepasan atau loncatan muatan listrik pada sebagian kecil sistem isolasi listrik dan tidak menjembatani ruang antara dua konduktor secara sempurna.
Peluahan sebagian dapat terjadi pada bahan isolasi padat, bahan isolasi cair maupun bahan isolasi gas. Berdasarkan lokasi terjadinya, peluahan sebagian dapat dikategorikan sebagai peluahan di dalam bahan isolasi, peluahan permukaan, dan korona. ${ }^{[2]}$

Peluahan pemukaan terjadi pada permukaan bahan isolasi seperti ditunjukkan pada gambar 2.1.a. Peluahan di dalam bahan isolasi terjadi akibat adanya ketidaksempurnaan pada bagian dalam bahan isolasi seperti ditunjukkan pada gambar 2.1.b. Sedangkan korona merupakan peluahan sebagian yang terjadi di bagian yang runcing pada konduktor metal yang ditunjukkan pada gambar 2.1.c.

Secara umum jenis-jenis peluahan sebagian terbagi atas:

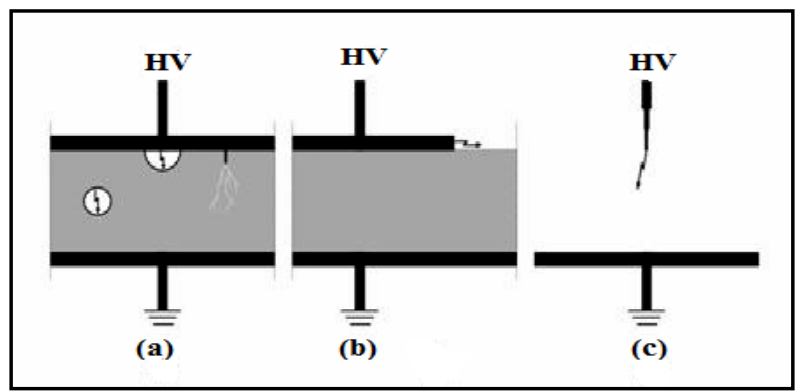

(a) peluahan rongga, (b) peluahan permukaan dan (c) peluahan korona

Gambar 2.1 Jenis Peluahan Sebagian

\section{Bahan Isolasi Polimer}

Polimer adalah merupakan substansi-substansi yang terdiri dari molekul makro yang panjang, dibentuk dari molekul kecil (monomer) atau sekumpulan molekul yang merupakan unit yang bersambungan.

Beberapa kelebihan yang dimiliki oleh isolator polimer yaitu ringan, kepadatan material polimer lebih rendah dibandingkan keramik maupun gelas, sehingga mudah dalam penanganan maupun instalasi, bentuk geometri sederhana, karena mempunyai karakteristik jarak rambat yang relatif besar menyebabkan desain isolator polimer sederhana, tahan terhadap polusi, karena bahan polimer mempunyai sifat menolak air (hydropobic) yang baik.

Sedangkan kekurangan yang dimilki oleh isolator polimer adalah penuaan/degradasi pada permukaannya (surface ageing), stress yang disebabkan antara lain karena korona, radiasi UV atau zat kimia dapat menyebabkan reaksi kimia pada permukaan polimer. $^{[3]}$

\section{Karet Silikon}

Karet silikon merupakan bahan sintetis yang mempunyai tahanan yang besar pada suhu tinggi. Bahan ini lebih mahal dibandingkan dengan bahan 
lainnya tetapi untuk pemakaian khusus dapat dibenarkan karena memberikan sifat yang lebih unggul pada kabel, dapat bekerja secara terusmenerus pada suhu sampai dengan $150^{\circ} \mathrm{C}$ dan bisa juga lebih, isolasi listrik tidak begitu kuat pada suhu normal. Karet silikon tetap lentur pada suhu yang sangat rendah tetapi tahan terhadap minyak seperti halnya karet alami sehingga perlu pencegahan untuk melindunginya. ${ }^{[4]}$

\section{E. Emisi Akustik}

Emisi akustik didefinisikan sebagai gelombang transien elastis yang dibangkitkan oleh pelepasan energi (rapid of energy) di dalam suatu material yang mengalami keretakan sehingga menghasilkan penyebaran sinyal dan deformasi internal di dalam suatu material/bahan. Emisi akustik merupakan salah satu pengujian yang tidak merusak (Non Destructive Testing). Beberapa pengujian tidak merusak lainnya seperti Ultrasonic, X-Ray, Edy Current, Liquid, dan Thermographic. ${ }^{[5]}$

\section{METODE PENELITIAN}

\section{A. Perancangan Alat Uji}

Gambar 3.1 adalah rangkaian pengujian yang dilakukan dalam tugas akhir ini. Tegangan tinggi terhubung pada elektroda jarum. Sementara elektroda pentanahan terhubung pada ground. Panjang elektroda jarum adalah $7 \mathrm{~cm}$ dengan diameter $3 \mathrm{~mm}$. Lebar elektroda pentanahan adalah $0.3 \mathrm{~cm}$ dengan diamater $13 \mathrm{~mm}$. Diantara elektroda terdapat sampel isolasi (yaitu karet silikon) dengan tebal $8 \mathrm{~mm} .{ }^{[6]}$ Pada titik tengah karet silikon dibuat lubang (hole) dengan diameter $3 \mathrm{~mm}$. Hal ini dilakukan untuk menghasilkan sumber peluahan sebagian jenis rongga.

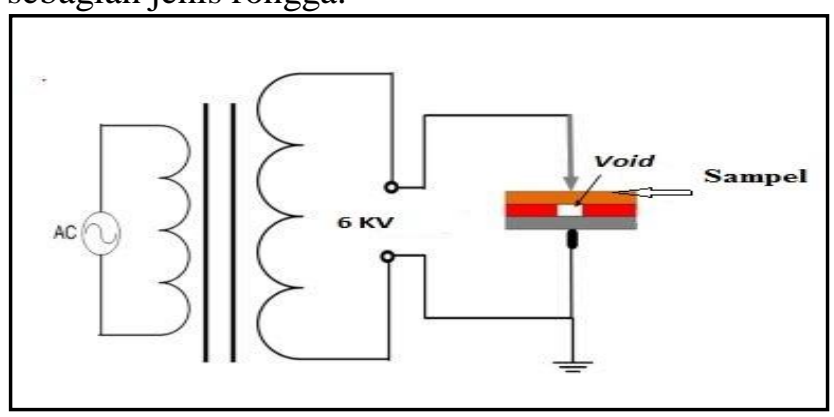

Gambar 3.1 Rangkaian pengujian isolasi rongga (void)

\section{B. Proses Pengujian Peluahan Sebagian}

1. Dipasang alat dan bahan sesuai dengan yang ada pada gambar 3.2.

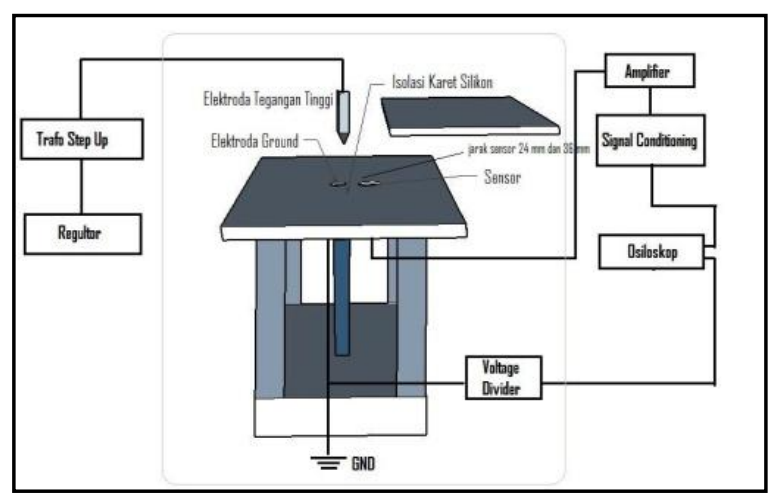

Gambar 3.2 Rangkaian Pengujian

2. Diukur tegangan output dari voltage regulator dan output trafo step-up dengan bantuan pembagi tegangan.

3. Diukur tegangan kritis pada isolasi karet silikon.

4. Dilakukan pengujian terhadap benda uji yaitu karet silikon pada 3 level tegangan dibawah dibawah tegangan kritis pada jarak $24 \mathrm{~mm}$ dan pada jarak $36 \mathrm{~mm}$ sampai timbulnya gelombang peluahan.

5. Dilakukan pengujian terhadap benda uji dengan dua cara yaitu menggunakan lubang tunggal dan lubang ganda.

6. Diambil data hasil pengujian berupa tegangan peluahan sinyal peluahan dan arus bocor yang ditampilkan osiloskop.

7. Disimpan data gelombang peluahan dengan format .csv. untuk proses analisa selanjutnya.

8. Dilakukan pengulangan pada langkah 2-4 untuk mendapatkan jumlah data yang cukup untuk pengolahan data.

\section{Proses Pengolahan Data}

Data hasil pengujian (tegangan peluahan) ditangkap oleh osiloskop kemudian disimpan dalam bentuk .csv, setelah itu data di import menggunakan software matlab dengan tools wavelet 1-D sehingga dapat menghasilkan besar tegangan peluahan dan frekuensi dominan. Hasil pengujian juga didapatkan tegangan peak to peak yang ditampilkan pada osiloskop yang digunakan untuk menghitung besar arus bocor (leakage current) dalam setiap pengujian yang dilakukan dengan menggunakan perbandingan dari voltage divider yang telah dibuat. 


\section{HASIL DAN PEMBAHASAN}

\section{A. Tahap Perekaman dan Pengolahan Data}

Langkah-langkah yang dilakukan dalam perekaman dan pengolahan data adalah:

1. Data sinyal peluahan dan sinyal arus bocor direkam melalui osiloskop dalam bentuk .csv file.

2. Mengolah data bentuk .mat pada software untuk melakukan denoised pemisahan noise dengan sinyal aslinya.

3. Data yang dalam format .txt digunakan untuk menentukan besar frekuensi dominan dengan menggunakan fungsi FFT pada software yang digunakan.

4. Menghitung nilai arus bocor dari tegangan yang ditangkap oleh osiloskop.

5. Menganalisis data dari pengolahan yang dihasilkan.

\section{B. Data Hasil Pengujian}

Pengujian lubang tunggal pada isolasi karet silikon dilakukan pada jarak (d) $24 \mathrm{~mm}$ dan $36 \mathrm{~mm}$ yaitu agar dapat diketahui pola peluahan dengan jarak yang berbeda dan juga untuk mengetahui jarak optimal sensor dalam menangkap sinyal peluahan. Setelah dilakukan pengujian didapatkan tegangan kritis pada jarak $24 \mathrm{~mm}$ sebesar $1.2 \mathrm{kV}$, sedangkan pada jarak $36 \mathrm{~mm}$ didapatkan tegangan kritis sebesar $1.3 \mathrm{kV}$.

1. Pengujian pada jarak $24 \mathrm{~mm}$

Pada pengujian $24 \mathrm{~mm}$ sinyal peluahan yang terdeteksi dapat dilihat pada gambar yang ditunjukan pada gambar 4.1

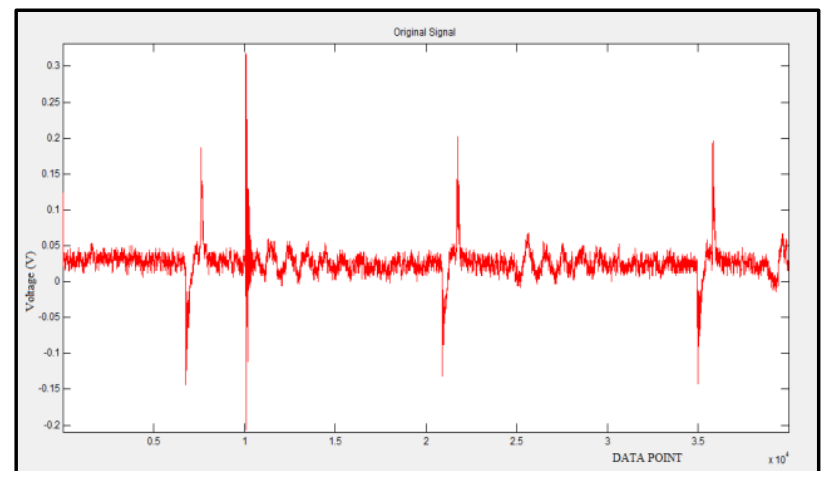

Gambar 4.1 Sinyal peluahan sebagian dengan Jarak 24 mm

Pada gambar 4.1 Sinyal peluahan diolah dan dilakukan denoised atau pemisahan sinyal asli dengan noisenya dengan menggunakan mother wavelet $D B 4$ Level 1. Untuk mengetahui karakteristik dari sinyal dilakukan analisis frekuensi dominan dan arus bocor. Dari pengujian yang didapat rentan frekuensi dominannya yang ditampilkan pada gambar 4.2

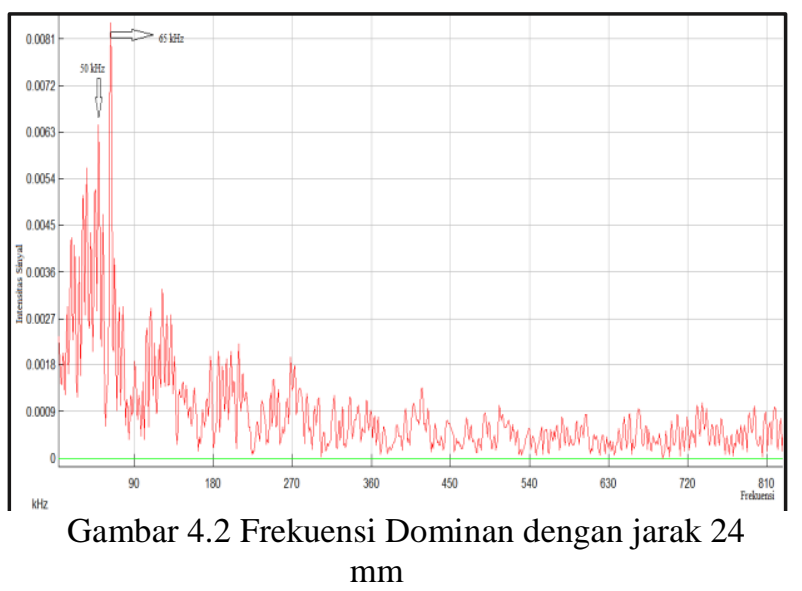

Pengujian arus bocor dilakukan dengan mengamati tegangan yang dibaca osiloskop tiap menitnya sampai terjadi peluahan sebagian, kemudian tegangan yang dibaca dikonversi menjadi arus untuk mengetahui arus bocornya. Data hasil pengujian peluahan sebagian pada isolasi karet silikon dengan jarak 24 mm dapat dilihat pada Tabel 4.1.

Tabel 4.1 Pengujian pada Jarak $24 \mathrm{~mm}$

\begin{tabular}{|c|c|c|c|}
\hline $\begin{array}{c}\text { Tegangan } \\
(\mathbf{k V})\end{array}$ & $\begin{array}{c}\text { Amplitudo } \\
\text { AE Signal }\end{array}$ & $\begin{array}{c}\text { Arus } \\
\text { Bocor } \\
(\mathbf{m A})\end{array}$ & $\begin{array}{c}\text { Frekuens } \\
\mathbf{i} \\
\text { Dominan } \\
(\mathbf{k H z})\end{array}$ \\
\hline 0.9 & 0.28 & 28.9 & $55-68$ \\
\hline 1.0 & 0.35 & 30.4 & $62-67$ \\
\hline 1.1 & 0.36 & 31.2 & $50-65$ \\
\hline
\end{tabular}

Pada tabel 4.1 menunjukkan hasil pengujian pada jarak $24 \mathrm{~mm}$ dimana tegangan uji yang digunakan adalah $1.1 \mathrm{kV}, 1.0 \mathrm{kV}, 0.9 \mathrm{kV}$ dan terlihat bahwa dengan kenaikan tegangan uji, maka terlihat kenaikan amplitudo AE Signal yang terekam oleh sensor dan juga kenaikan arus bocor yang terjadi saat peluahan. Hal ini dapat diperlihatkan pada gambar 4.3.

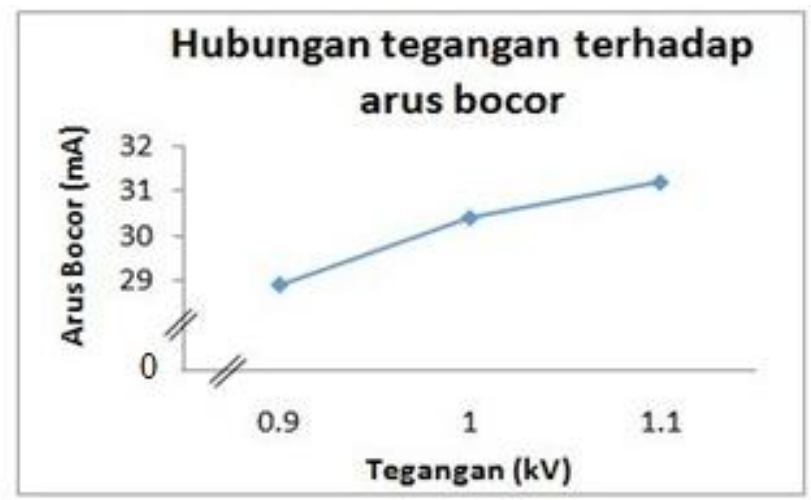

Gambar 4.3 Grafik Hubungan Tegangan dan Arus Bocor 
Gambar 4.3 menunjukkan hubungan Arus Bocor pengujian dengan tegangan uji pada jarak $24 \mathrm{~mm}$ yaitu semakin besar tegangan uji maka nilai arus bocor pun akan semakin besar dengan kata lain berbanding lurus.

\section{Pengujian Pada Jarak $36 \mathrm{~mm}$}

Pada pengujian $36 \mathrm{~mm}$ sinyal peluahan yang terdeteksi dapat dilihat pada gambar yang ditunjukan pada gambar 4.4.

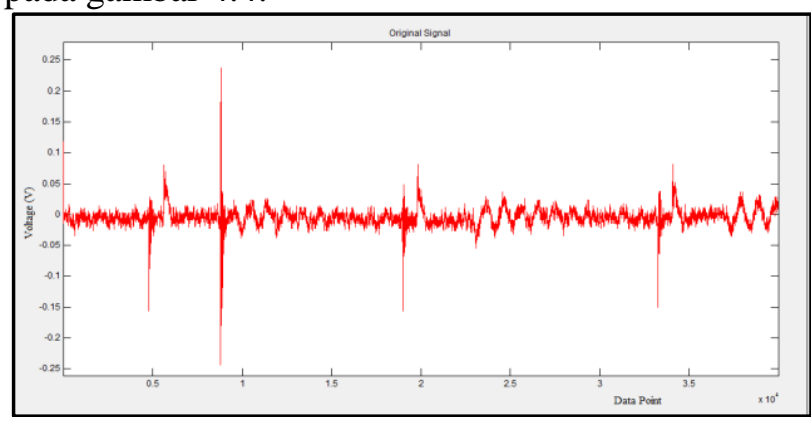

Gambar 4.4 Sinyal peluahan sebagian pada jarak $36 \mathrm{~mm}$

Pada gambar 4.4 Sinyal peluahan diolah dan dilakukan denoised atau pemisahan sinyal asli dengan noisenya dengan menggunakan mother wavelet $D B \quad 4$ Level 1. Untuk mengetahui karakteristik dari sinyal dilakukan analisis frekuensi dominan dan arus bocor. Dari pengujian yang didapat rentan frekuensi dominannya yang ditampilkan pada gambar 4.5.

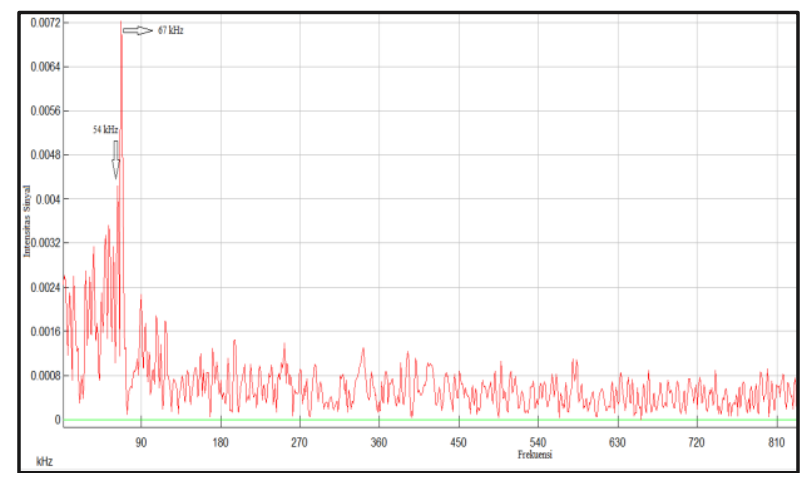

Gambar 4.5 Frekuensi Dominan pada jarak 36 $\mathrm{mm}$

Kemudian pengujian arus bocor pada jarak $36 \mathrm{~mm}$ dilakukan dengan mengamati tegangan yang dibaca osiloskop tiap menitnya sampai terjadi peluahan sebagian, kemudian tegangan yang dibaca dikonversi menjadi arus untuk mengetahui arus bocornya. Data hasil pengujian peluahan sebagian pada isolasi karet silikon dengan jarak $36 \mathrm{~mm}$ dapat dilihat pada Tabel 4.2.

Tabel 4.2 Pengujian pada jarak $36 \mathrm{~mm}$
\begin{tabular}{|c|c|c|c|}
\hline $\begin{array}{c}\text { Tegangan } \\
(\mathbf{k V})\end{array}$ & $\begin{array}{c}\text { Amplitudo } \\
\text { AE Signal }\end{array}$ & $\begin{array}{c}\text { Arus } \\
\text { Bocor } \\
(\mathbf{m A})\end{array}$ & $\begin{array}{c}\text { Frekuensi } \\
\text { Dominan }\end{array}$ \\
\hline 1.0 & 0.31 & 31.6 & $53-67$ \\
\hline 1.1 & 0.32 & 32.8 & $57-63$ \\
\hline 1.2 & 0.32 & 33.6 & $54-67$ \\
\hline
\end{tabular}

Pada tabel 4.2 menunjukkan hasil pengujian pada jarak $36 \mathrm{~mm}$ dimana tegangan uji yang digunakan adalah $1.2 \mathrm{kV}, 1.1 \mathrm{kV}, 1.0 \mathrm{kV}$ dan terlihat bahwa dengan kenaikan tegangan uji, maka terlihat kenaikan amplitudo AE Signal yang terekam oleh sensor dan juga kenaikan arus bocor yang terjadi saat peluahan. Hal ini dapat diperlihatkan pada gambar 4.6.

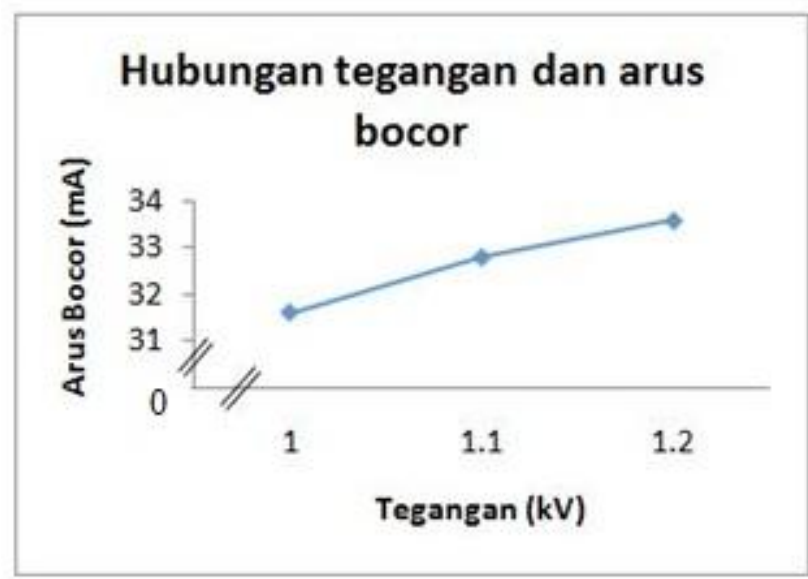

Gambar 4.6 Grafik Hubungan Tegangan dan Arus Bocor

Gambar 4.6 menunjukkan hubungan Arus Bocor pengujian dengan tegangan uji pada jarak $36 \mathrm{~mm}$ yaitu semakin besar tegangan uji maka nilai arus bocor pun akan semakin besar dengan kata lain berbanding lurus.

3. Perbandingan Pengujian Pada Jarak $24 \mathrm{~mm}$ dan $36 \mathrm{~mm}$

\section{$\checkmark$ Frekuensi Dominan}

Perbandingan pengujian pada jarak $24 \mathrm{~mm}$ dan $36 \mathrm{~mm}$ tentang besar frekuensi dominan yaitu besar nilai rentan frekuensi dominan pada jarak $24 \mathrm{~mm}$ dan $36 \mathrm{~mm}$ hampir sama (lihat pada tabel 4.1 dan tabel 4.2) yaitu memiliki rerata frekuensi dominan disekitar $60 \mathrm{kHz}$. Akan tetapi, pada penelitian mengenai diagnosis kerusakan isolasi dari Ethylene Propylene Rubber $(\mathrm{EPR})^{[6]}$ menggunakan teknik emisi akustik didapatkan besar frekuensi dominan sebesar $70 \mathrm{kHz}$. Dapat disimpulkan bahwa besar frekuensi dominan yang didapat hampir sama kemungkinan karena struktur isolasi Ethylene Propylene rubber hampir mirip dengan silicone rubber sehingga didapatkan 
besar frekuensi dominan yang hampir sama dibawah $100 \mathrm{kHz}$.

\section{Tegangan dan Arus Bocor}

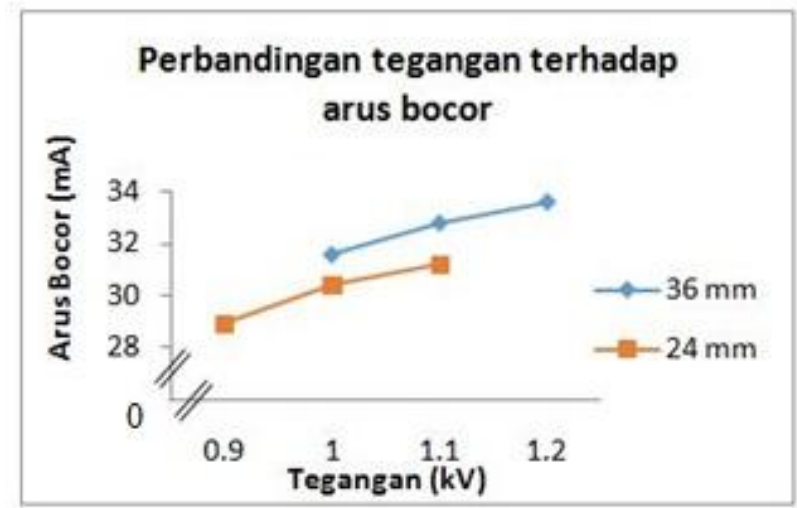

Gambar 4.7 Perbandingan Grafik Tegangan dan Arus Bocor

Berdasarkan gambar 4.7 diatas diketahui bahwa untuk perbandingan antara jarak $24 \mathrm{~mm}$ dan $36 \mathrm{~mm}$ yaitu untuk besar tegangan terhadap arus bocor, semakin jauh jarak sensor maka akan semakin besar arus bocor yang ditangkap, yang disebabkan oleh dua kemungkinan yaitu (1) semakin jauh jakak sensor semakin besar teganan uji yang digunakan, dan (2) semakin jauh jarak sensor akan mengakibatkan terjadinya akumulasi muatan yang mengalir/menumpuk yang akan ditangkap oleh sensor emisi akustik. Dapat disimpulkan bahwa perbandingan antara tegangan dan arus bocor yaitu berbanding lurus. Dapat dilihat juga pada tegangan yang sama yaitu $1.1 \mathrm{kV}$ antara jarak $24 \mathrm{~mm}$ dan 36 $\mathrm{mm}$ yang memiliki arus bocor yang lebih besar yaitu pada jarak $36 \mathrm{~mm}$.

\section{SIMPULAN DAN SARAN}

A. Kesimpulan

Setelah melakukan proses pengujian serta analisa data maka diperoleh simpulan sebagai berikut:

1. Saat peluahan sebagian terjadi secara terus menerus maka arus bocor yang dihasilkan akan semakin besar.

2. Pada pengujian isolasi karet silikon dengan lubang tunggal pada jarak $24 \mathrm{~mm}$ dan $36 \mathrm{~mm}$ didapatkan rentang frekuensi dominan disekitar $60 \mathrm{kHz}$.

3. Perbandingan antara tegangan terhadap arus bocor pada jarak sensor $24 \mathrm{~mm}$ dan $36 \mathrm{~mm}$ yaitu berbanding lurus yaitu semakin besar tegangan maka arus bocor akan semakin besar.

B. Saran

Saran dari penelitian ini adalah:

1. Penelitian lebih lanjut mengenai pendeteksian beragam sumber peluahan sebagian sebaiknya dilakukan dengan menggunakan sumber tegangan yang memiliki kapasitas tegangan yang lebih besar, sensor yang sensitif dan terhindar dari inteferensi gelombang gangguan (noise), sehingga dapat diperoleh karakteristik gelombang peluahan sebagian secara jelas dari peluahan yang menghasilkannya.

2. Penelitian lebih lanjut sebaiknya menggunakan jumlah titik (data) pada osiloskop lebih banyak agar dapat mengetahui banyaknya interval antara peluhan sebagian yang terjadi dalam suatu pengujian, hal ini dapat berpengaruh terhadap karakteristik frekuensi yang didapatkan.

\section{DAFTAR PUSTAKA}

[1] Tobing, Bonggas L. Dasar Teknik Pengujian Tegangan Tinggi. Gramedia. Jakarta. 2003. pp.12

[2] Frederik H, Kreuger. Partial Discharge Detection. Butterworth. London. 1989

[3] Anisa. Modul Konstruksi Isolator Dalam Sistem Distribusi, (online), (http://annisaniesya7.blogspot.com/2012/06/ hmmmmmmm.html, diakses 09 september 2014).

[4] Munteanu, R. Silicone insulator use on the rise worldwide: Transmission and Distribution. London. 1996

[5] Richard D. Finleyson. Handbook of Non destructive Evaluation chapter 10 Acoustic Emission Testing. McGraw-Hill Companies. 2003. Pp 10-10.39.

[6] Nainggolan. Jannus, et al. Diagnostics of Insulation Deterioration of Ethylene Propylene Rubber Using an Accoustic Emission Technique. IEEE Transactions on Dielectrics and Electrical Insulation. Vol. 17. Issue 4. 2010. Pp. 1242-1248. 